\title{
Um território improvável para um improvável grupo. Ações em torno de um espaço
}

\author{
Juliana Crispe*
}

\section{Resumo:}

Esta pesquisa propõe uma reflexão acerca da cidade, do esquecimento, da fotografia, de ações geradas por um grupo de jovens artistas que tem em comum a paixão pela fotografia, pela história da fotografia, pelos equipamentos fotográficos, pelas possibilidades de construção de imagem, seja ela através dos meios tradicionais ou através da tecnologia apresentada para nós hoje. Tudo isso alinhado pelo desejo de fundar um foto-clube, por artistas que buscam a ampliação das possibilidades do ato de fotografar, juntamente com a linguagem artística trabalhando a fotografia com distintas formas.

\section{Palavras-Chave:}

Fotografia; ações; cidade; Território Improvável

Improvável Grupo é formado pelos artistas-fotógrafos-etc: Juliana Crispe, Bruno Ropelato, Marina Borck, Monique Bens, Tiaraju Verdi. O grupo iniciou-se em 2008; entre tantas entradas e saídas, encontros e desencontros de membros participantes, no começo deste ano (2009), o foto-clube fixou-se em cinco integrantes que continuaram a proposta de trabalhar o meio fotográfico, construindo um grupo fixo e integrado. Todos integrantes são alunos e ex-alunos do Curso de Artes Visuais da Universidade do Estado de Santa Catarina.

O termo Etc aqui faz referência ao curador, professor, crítico e artista Ricardo Basbaum, em seu texto "Amo os artistas-etc" apresentado na Documenta de Kassel, no ano 2004.

Segundo Basbaum (2004),

Quando um artista é um artista de tempo completo, poderíamos chamá-lo de "artistaartista", quando o artista questiona a natureza e função de seu leque de possibilidades, poderíamos chamar "artista-etc", portanto, podemos imaginar várias categorias: (artistacurador, artista-escritor, artista-ativista, artista-produtor, artista-agente, artista-teórico, artista-terapeuta, artista-docente, artista-químico, etc)...

Ou seja, ele entende o artista contemporâneo como um agente composto por multiplicidades, que trabalha com diversas linguagens e conexões.

Assim sendo, o grupo de fotógrafos artistas-etc trabalham com linguagens múltiplas e através dos hibridismos presentes na pesquisa individual de cada um,

* Mestranda no Programa de Pós-Graduação em Artes Visuais da UDESC. 
trazem colaborações para os projetos desenvolvidos pelo grupo.

Entendemos a ação de fotografar como extensão do nosso corpo que registra, vivencia o espaço. Que possibilita através da experiência, um além no que está presente na imagem fotográfica.

Diante de tantas experimentações acerca da imagem fotográfica e estudos sobre fotografia, fotógrafos e artistas, traçamos um projeto sobre percursos na cidade, intitulado "Território Improvável" construindo assim, o primeiro projeto efetivo que se desenrolou em ações produzidas pelo grupo.

"Território Improvável" parte da busca por espaços urbanos que tenham como principal característica a transitoriedade e o abandono. As primeiras imagens fotográficas deste projeto referem-se a um espaço que se constitui de um casarão abandonado e de vestígios de demolições. Após algumas investigações sobre o espaço, descobrimos que o foco para os registros fotográficos da ação planejada era uma das casas mais antigas do centro de Florianópolis e que foi de um ilustre político e engenheiro da cidade, Hercílio luz. Além de ser um espaço-memória da cidade, o espaço é carregado de histórias e abandonado.

Esta casa situa-se na Avenida Mauro Ramos, um casarão em ruínas. Foi residência do ex-governador Hercílio Luz, que nasceu em 1860 e faleceu em 1924, nesta residência.

Segundo informações encontradas no Site do DEINFRA - Departamento Estadual de Infraestrutura, em julho de 2009:

Entre prédios modernos, a casa hoje deteriorada foi construída no ano de 1848; abandona há décadas, era conhecida como Chácara do governador Hercílio Luz. A planta urbana da casa foi desenhada por Otto Karl Schlappel, e consta como uma das mais antigas da cidade de Florianópolis.

Não foi encontrada a data de quando Hercílio Luz passou a residir nesse endereço. O terreno foi doado ao governador por um amigo e pertenceu ao governador em usufruto até a sua morte.

A arquitetura eclética da casa é uma evolução urbana para a cidade da época; a implantação de chácaras no final do século XIX demonstra a mudança da ocupação tradicional do solo urbano, que, no século XX, desaparecem do Centro da cidade. O casarão está no único terreno remanescente desse tipo de ocupação.

A primeira reforma da casa é realizada ainda por Hercílio Luz, em 1921. Originalmente o casarão tinha apenas um andar, mas em 1954, foi construído mais um pavimento.

Os variados usos do prédio acabaram por contribuir para a alteração arquitetônica e o desgaste acelerado do casarão. Primeiro, foi moradia da família Luz, depois sede do Clube Senzala, Serviço de Atendimento e Prevenção à Malária, Pronto Socorro Psiquiátrico do Instituto São José, sendo também moradia da família Muniz, que alugou o casarão, por mais de uma década, até início dos anos 90. Por último, transformou-se em depósito de uma oficina mecânica instalada num anexo do casarão.

A casa é um patrimônio histórico do Estado, mas sua restauração esbarra em vários problemas. O primeiro deles é a falta de recursos do governo do Estado. O outro é que as leis de incentivo ao patrimônio histórico e à cultura não podem ser usadas porque a área, 
apesar de tombada, pertence à família Polli (sucessores dos antigos proprietários do terreno).

Um grupo de arquitetos e técnicos ligados ao Departamento Estadual de Infraestrutura (Deinfra) e ao Instituto de Planejamento Urbano de Florianópolis (IPUF) buscam encontrar uma solução que atenda à legislação, aos interesses da comunidade e aos donos da área. Pela lei, o proprietário é responsável pela manutenção do prédio, mas, o governo está empenhado a chegar a um termo que seja adequado para a recuperação do imóvel - segundo a diretora de planejamento do IPUF, a arquiteta Cristina Piazza.

Segundo estudo do Núcleo de Restauração do Deinfra, a idéia é fazer no local o Parque da Chácara Governador Hercílio Luz, um grande centro cultural com ampla área verde no Centro da cidade, com recuperação do paisagismo e garantia de acesso público.

Uma das soluções para viabilizar a restauração do casarão seria a doação do terreno ou parte dele para o Estado.

Essas questões levantadas sobre este patrimônio aparecem na mídia, após a primeira ação e exposição feita pelo Improvável Grupo. A primeira exposição foi realizada no dia 23 de maio deste ano, sendo que informações sobre o espaço aparecem no site do Deinfra em 21 de julho de 2009 e no jornal de circulação estadual "Diário Catarinense", no dia 13 de agosto de 2009.

A partir de percepções coletivas e individuais do grupo e de ações performáticas, foram elaboradas imagens fotográficas que expuseram tanto aspectos mínimos daquele espaço, como sua relação com a extinta presença humana.

Nesta proposta específica há a preocupação de discutir pontos como a deterioração de espaços urbanos e sua gradativa transformação de sentidos. A fotografia surge, então, como outra visibilidade possível para espaços em progressivo esquecimento.

As fotografias estão intimamente ligadas a ações performáticas que estabelecem fabulações sobre o espaço, além de a própria ação tornar-se um ativador desta outra visibilidade e uma forma de interação do grupo com o ambiente.

O grupo se baseia nos estudos situacionistas sobre o uso da cidade. O movimento da Internacional Situacionista, de cunho político e artístico, foi ativo no final da década de 60 e aspirava por transformações políticas e sociais, tendo a sua frente o francês Guy Debord, grande ativista político, que em 1967 escreve seu livro A sociedade do espetáculo. O pensamento e manifestações da Internacional Situacionista sobre o uso dos espaços da cidade servem como referência para o Improvável Grupo, como em uma das suas frases mais conhecidas:

Cidadãos de todos os países, derivem! Dissolvam as fronteiras e destruam os muros de todos os tipos, das prisões e asilos aos condomínios residenciais fechados, dos shoppings centers aos conjuntos habitacionais modernos! (JACQUES, 2003)

Neste sentido, não é proposta do grupo uma construção documental do espaço apenas. A proposta reúne elementos relativos à vivência neste lugar e deslocá-los para outros espaços. Os trajetos multiplicam-se, não ficando apenas restritos ao 
movimento do grupo. Passam a incluir o movimento do próprio espectador, que a cada proposta de exposição, refletida por especificidades dos lugares, reconstrói narrativas e transforma o espaço de abandono em espaço para conjecturas poéticas.

O artista hoje é um propositor de ações, que cria relações e proporciona através de projetos, possíveis vivências, trazendo a referência da arte mais próxima do espectador que passa a ser participador e perceptor das ações artísticas. No texto de Nicolas Bourriaud, O que é um artista (hoje)?, fica presente o lugar do artista no espaço da contemporaneidade. "Um artista é o avião furtivo da cultura: imperceptível ao radar do espetáculo, porém extremamente eficaz por sempre apontar para os lugares afiados, para as situações mais críticas" (BOURRIAUD, 2003, p.77).

Ao fotografarmos os detalhes do espaço, as paredes em quase ruínas, os vidros quebrados, o mato em grande altura ao redor da casa e o espaço do entorno, nos terrenos baldios que cercam o Território Improvável, fazemos, assim, uma crítica através das ações e imagens geradas. A casa é rodeada por novas construções e terrenos abandonados e parece ser engolida pela nova Florianópolis, que há pouco pôde perceber esse espaço, devido à demolição da casa presente no terreno da frente, ficando um pouco mais visível para quem passa pela Avenida Mauro Ramos a casa que até então era escondida.

\section{Território improvável - em três tempos e outros prováveis... Tempo 1 -}

A primeira exposição, realizada em 23 de maio a 23 de junho, aconteceu no Bar Taliesyn, situado no centro de Florianópolis. Um rock bar, que tem como característica receber um público que se interessa por rock. O espaço encontra-se na Rua Fernando Machado, no 36, subindo as escadarias, no segundo andar. Próximo à praça XV.

Ao propormos uma exposição num espaço não convencional, nos utilizamos de um recurso que pudesse dialogar com os freqüentadores e com o ambiente. Usamos como suporte das fotos, porta-copos, produzidos com as fotografias feitas no "Território Improvável", juntamente com a ata escrita por Fabíola Scaranto, relatando a primeira ação/invasão no espaço, fixada numa das paredes, ao lado, e um mapa desenhado por Monique Bens, localizando o espaço. Além disso, era possível encontrar numa das janelas do Bar a escada utilizada pelo grupo, para pular o muro da casa. O acesso à casa se dava pela entrada de uma oficina mecânica que se encontra lacrada, ou, a segunda opção usada pelo grupo, o terreno vizinho frontal na Avenida Mauro Ramos. O quintal é cercado por grades com placas indicando corrente elétrica, puro blefe que não afastou da residência moradores de rua, e nem punks que, no ano passado, invadiram a casa, fazendo dela sua moradia.

Por uma escada de cordas, seis artistas invadiram um espaço em ruínas. Entre camisinhas, seringas, sapatos, roupas etc., passando pela agressividade dos moradores de rua, moradores na época da primeira invasão/ação, nos restringimos 
ao espaço externo da casa, propondo e registrando ações entre escombros, árvores e passantes fortuitos.

Criado com o objetivo de trabalhar questões relacionadas à fotografia, o grupo expôs pela primeira vez o resultado de sua produção. A partir de elementos integrados ao ambiente escolhido para a exposição, a proposta suscitou a construção de histórias ficcionais. O ponto de partida é o espaço urbano e sua relação com o cotidiano. A exposição também visava à interação entre o público, favorecida pelo próprio ambiente. Logo na abertura da exposição houve a participação dos espectadores, que levaram os porta-copos, e o grupo não fez objeção a tal ato. Assim sendo, o que ficou até o final da exposição, foi: a ata e o mapa fixados na parede, a escada pendurada na janela e as fotografias que ficavam rodando, à mostra, na televisão do Bar.

\section{Tempo 1 - Imagens - Bar Taliesyn}
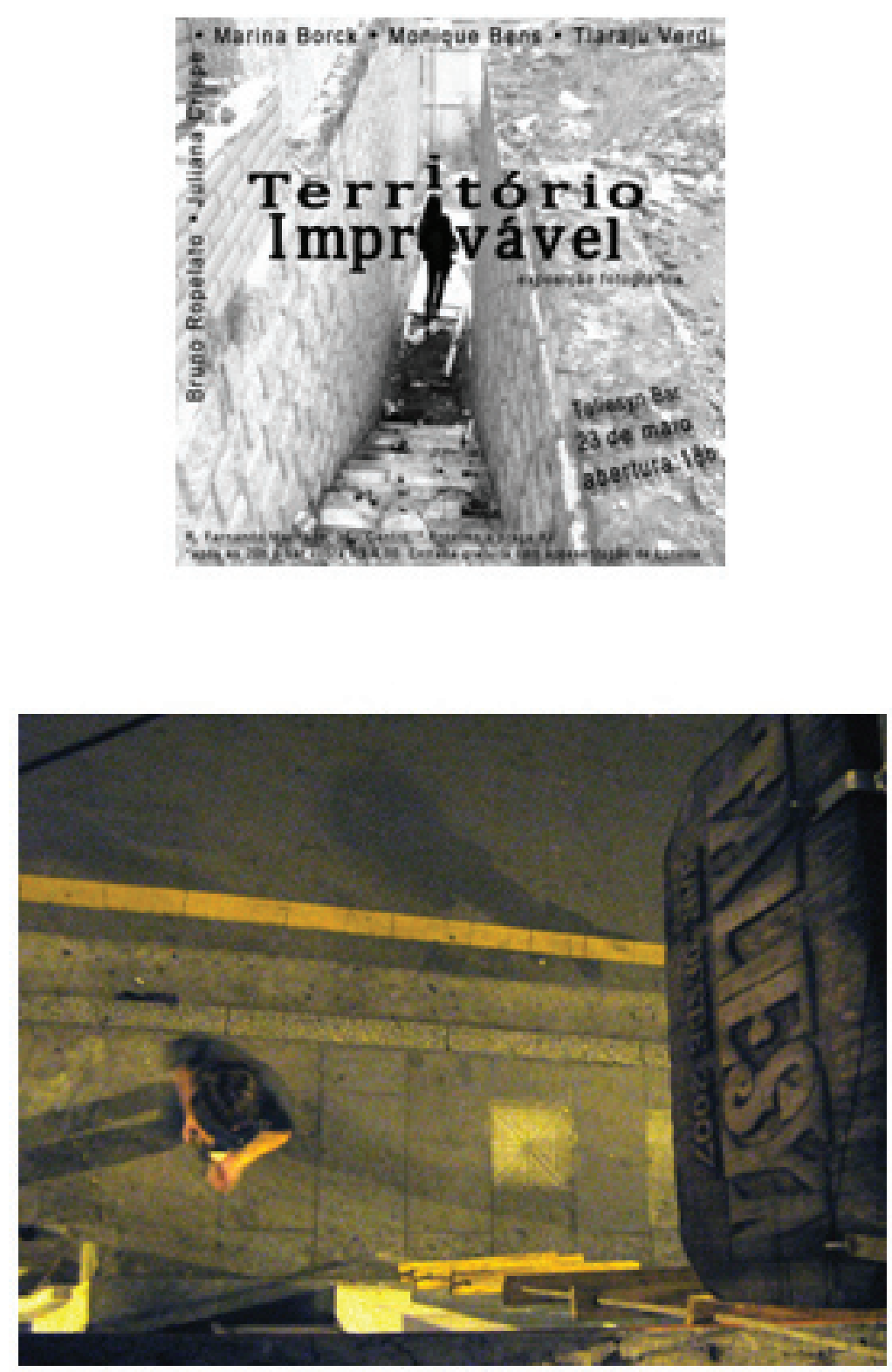

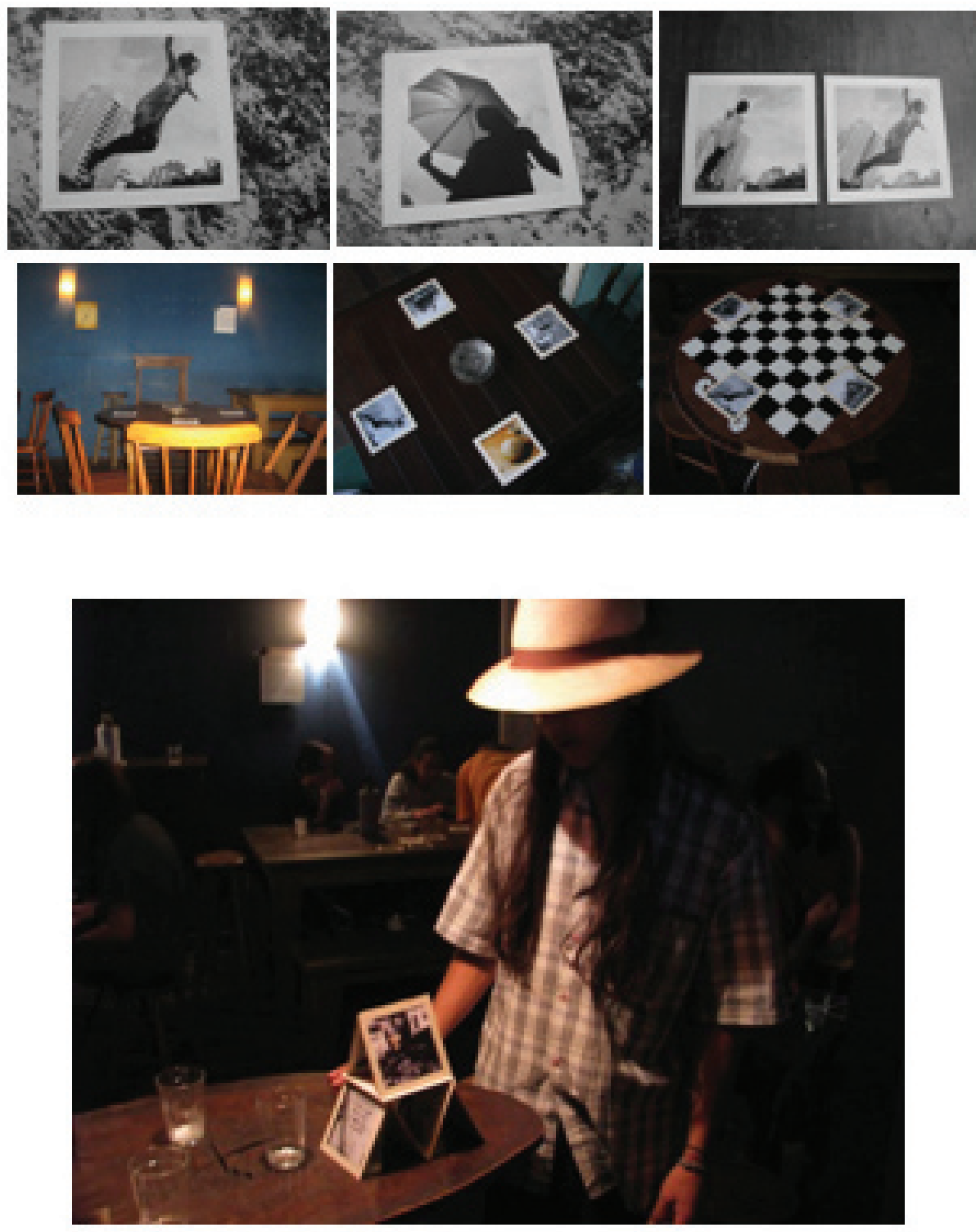

\section{Tempo 2}

A segunda mostra do "Território Improvável" aconteceu no Memorial Meyer Filho, na Praça XV de Novembro, no 180, na esquina com Tiradentes, Centro. A exposição seria realizada de 27 de agosto a 11 de setembro, mas a pedido da coordenação do espaço se alongou até dia 05 de outubro.

Nesta mostra, ficam evidenciadas as ações performáticas em torno do espaço. Entende-se nesse sentido que a ação do corpo é o que produz percursos e que possibilita gerar imagens. Não se trata de registros de performances, mas de ações feitas para a fotografia. Mesmo que este corpo não fique evidenciado em todas as imagens fotográficas, ele se faz presente pelo olhar que registra o momento e a ações feitas e compartilhadas pelo grupo.

As fotografias libertam-se da autoria individual, sem hierarquias, sem etiquetas na parede, assumindo as fotos geradas como uma produção do grupo. 
Além das fotografias, era possível encontrar no espaço expositivo os elementos que conduziram as ações fotográficas, como novamente a escada utilizada para adentrar o espaço, pendurada na parede esquerda, e o mapa desenhado com giz na parede preta ao fundo da galeria, localizando as ações, o "território improvável", percursos produzidos pelo grupo, o local de encontro para as reuniões "Fundação Cultural Badesc", o bar Taliesyn que abrigou a outra exposição e o próprio espaço do Memorial Meyer Filho.

Criou-se uma instalação, cenário, suscitando ao espectador querer saber e vivenciar o território improvável.

Luiz Rogério, no seu texto para revista Concinnitas, do Instituto de Artes da Universidade Estadual do Rio Janeiro, no 7, de julho de 2006, fala do artista e de seu olhar.

Segundo ele:

O artista trabalha exatamente como um diretor que seleciona, de fato, o que vai se passar na frente da câmera. E a exposição é isto: um filme sem câmera, uma película sobre a qual registramos uma ação, uma forma. Em troca, o espectador pode de algum modo organizar sua própria seqüência da exposição. Os artistas contemporâneos são, portanto, diretores, essa é sua condição natural, quase espontânea." (ROGÉRIO, 2006, p. 93)

Durante a exposição foi lançada uma convocatória, divulgada no espaço expositivo, por e-mail, cartazes, sites, panfletos:

Improvável Grupo convida a todos para um percurso/ação a se realizar neste sábado, 19.09, às 14h. O ponto de encontro é no Memorial Meyer Filho (prédio do Arquivo Histórico de Florianópolis, próximo à Praça XV) com saída às 14h30. O percurso integra a proposta Território Improvável que concebe o espaço urbano como ativador de percepções múltiplas.

O destino é um casarão abandonado na avenida Mauro Ramos (próximo ao shopping Beira-Mar). Este espaço deu origem às fotografias e aos objetos apresentados no Memorial Meyer Filho. A proposta agora é que os participantes deste percurso possam criar suas próprias ações e imagens partindo deste mesmo ambiente. Como trazer visibilidade a um espaço em situação de abandono? Objetos, figurinos, produção de imagens, performances... Traga máquina fotográfica, filmadora, idéias...

Aqui novamente podemos lembrar a Internacional Situacionista: O pensamento urbano situacionista estaria então baseado na idéia de construção de situações. Era situacionista "o que se referia à teoria ou à atividade prática de uma construção de situações". Uma situação construída seria então um "momento da vida, concreta e deliberadamente construído pela organização coletiva da ambiência unitária e de um jogo de acontecimentos" (JACQUES, 2003, p. 23).

\section{Tempo 2 - Imagens - Memorial Meyer Filho}



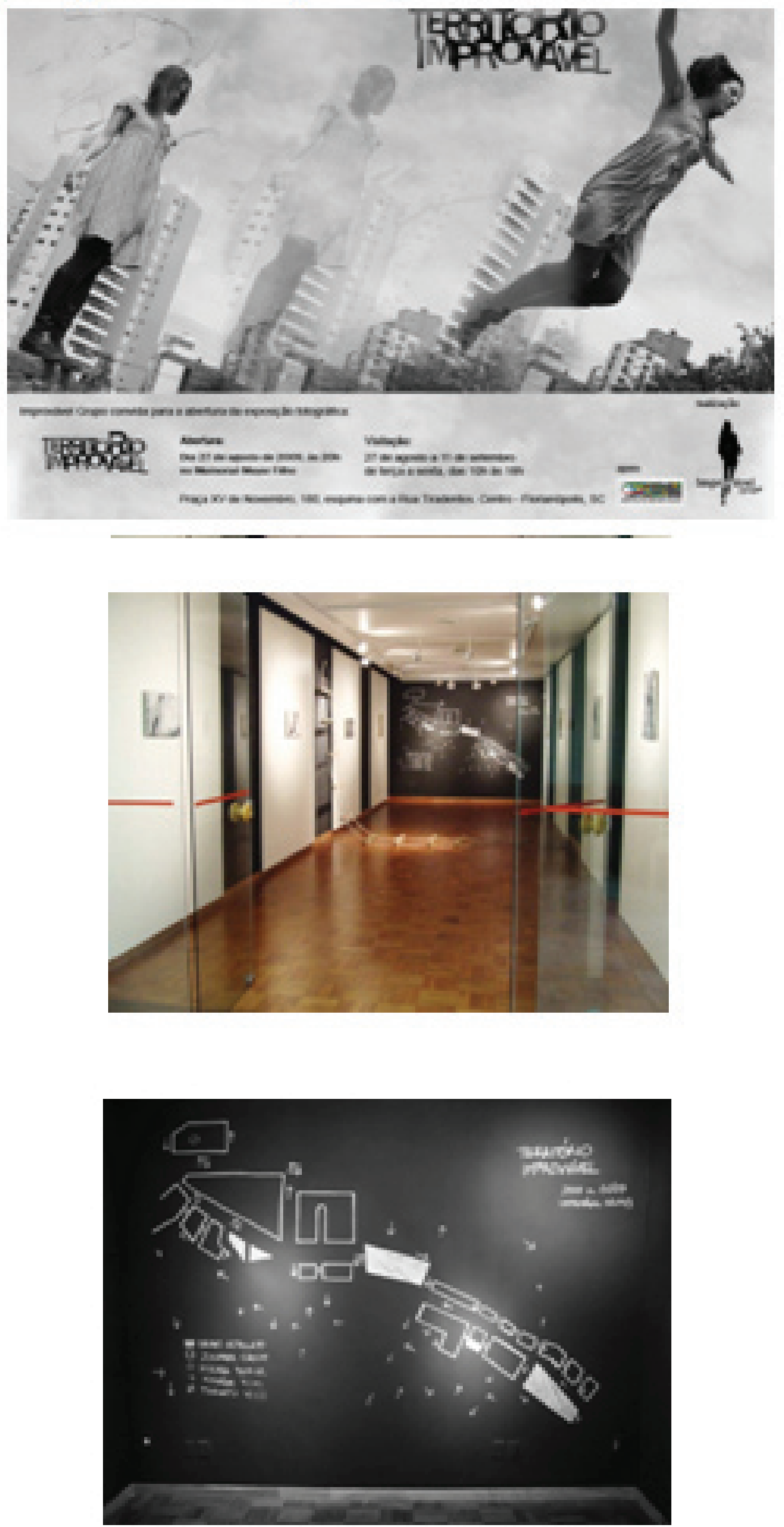

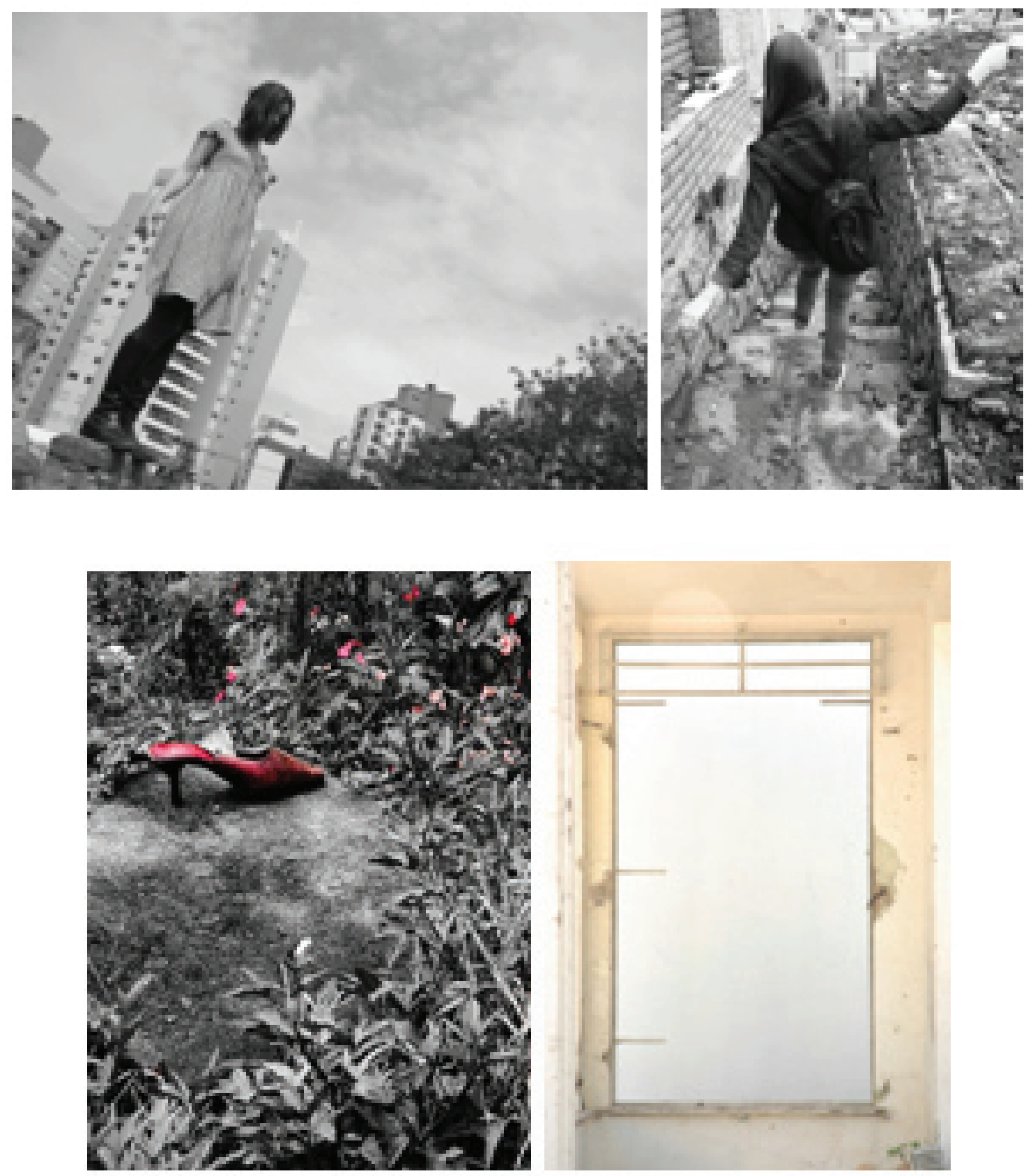

\section{Tempo 3 - Convocatória Percurso/Ação}

O território improvável partiu da foto-performance desenvolvida pelo improvável grupo que se infiltrou em alguns lugares da cidade; pensando na extensão das possibilidades e nas possíveis relações do espaço com outros participantes, abrimos a convocatória para quem quisesse participar.

A ação realizada no dia 19 de setembro contou com alguns participantes, não apenas da área de artes, mas pessoas que, ao receberem o convite encaminhado, se dispuseram a participar do percurso até o território improvável.

Com a ação/percurso, o grupo e os participantes puderam compartilhar, em uma tarde, diversas ações vivenciadas no entorno da casa e na parte interna.

Instalou-se um clima de fabulação, nostalgia e indignação, ao ver um espaço com uma beleza peculiar destruída e dada ao acaso. 
Julio Le Parc (2006, p. 199-200), artista argentino radicado em Paris desde 1958, um dos grandes nomes mundiais da arte cinética e artista que se caracteriza pela coerência de aproximar arte do público, sem cair no didatismo ou na superficialidade, ao se referir ao papel intelectual do artista na sociedade nos fala:

Ora, hoje em dia torna-se mais evidente a necessidade de questionar o papel do artista na sociedade. É preciso adquirir uma lucidez maior e multiplicar as iniciativas na difícil posição daquele que, ao mesmo tempo em que está imerso em uma determinada realidade social, e, ao mesmo tempo em que compreende sua situação, tenta tirar partido das possibilidades que se apresentam para produzir mudanças.

Quando as pessoas começam a ver com seus próprios olhos, quando constatam que os esquemas mentais que as aprisionam estão longe de sua realidade cotidiana, as condições estão maduras para uma ação de destruição desses esquemas.

Julio Le Parc não se contenta em acolher o espectador com sua arte cinética, aquela que incorpora o movimento e confunde o olhar. Desde a década de 60, ele mantém um forte ativismo político. No seu mundo ideal, as coisas só fazem sentido se puderem ser desfrutadas por todos, sem restrições.

No percurso/ ação, as fotografias são geradas em diversos momentos, registro das ações feitas pelos participantes que aceitaram o convite da convocatória gerada pelo grupo como possibilidade de encontros e múltiplas ações, experiências, vivências de um espaço até então experimentado apenas pelo grupo. Ações encenadas para câmera fotográfica, ações feitas para o espaço que são arquivadas pelo olhar dos participantes, dos fotógrafos, e novamente a ação do corpo que busca registrar através da participação não apenas o que fica por trás da câmera fotográfica.

As imagens não revelam uma supremacia fotográfica, o domínio pleno da técnica, pois elas, as imagens, buscam apenas ser uma extensão da ação produzida. Não é a imagem perfeita, mas o entendimento do artista enquanto corpo pulsante, que busca se relacionar ao espaço da cidade, ao percurso, ao ponto de partida, aos integrantes e convidados.

Ainda destacando palavras de Le Parc (Idem, p. 200), trata-se de despertar a capacidade potencial das pessoas para participarem, para decidirem por si mesmas - e levá-las a se relacionarem com outras pessoas para desenvolverem uma ação comum, de modo que venham a desempenhar um papel real em tudo aquilo que forma suas vidas.

Assim sendo, pudemos compartilhar em conjunto momentos de reflexão sobre a degradação, o esquecimento e a própria natureza humana, através um espaço de areia movediça, que sofre a ação do tempo e as mudanças de seu entorno. Do descaso e do seu possível desaparecimento.

A busca de ações participativas é criar rizomas, deslocamentos e redes. Citando novamente Luiz Rogério: 
nação e não por subordinação - é uma arte de efeitos comunicativos encadeados: a ênfase é dada não à forma, mas às materialidades, os dispositivos, aos processos e aos conceitos que ali se justapõem. Esse conjunto é colocado a serviço da interatividade e da participação e visa a algum tipo de influência, que convoque uma ação. Tal ação decorre dos objetivos inscritos, pelo conceito, nos dispositivos que devem ser processados. A arte de rede é uma arte da motricidade mais do que da percepção, dos deslocamentos físicos mais do que da contemplação estática, os quais se efetivam por meio de conexões horizontais, sem hierarquia nem centralidade... O participante responde à obra com atos comunicativos, selecionáveis e atualizáveis singularmente no interior das virtualidades abertas... (ROGÉRIO, 2006, p. 93).

\section{Tempo 3 - Imagens - Convocatória Percurso/Ação. Ações do Improvável Grupo e dos participantes da Convocatória}

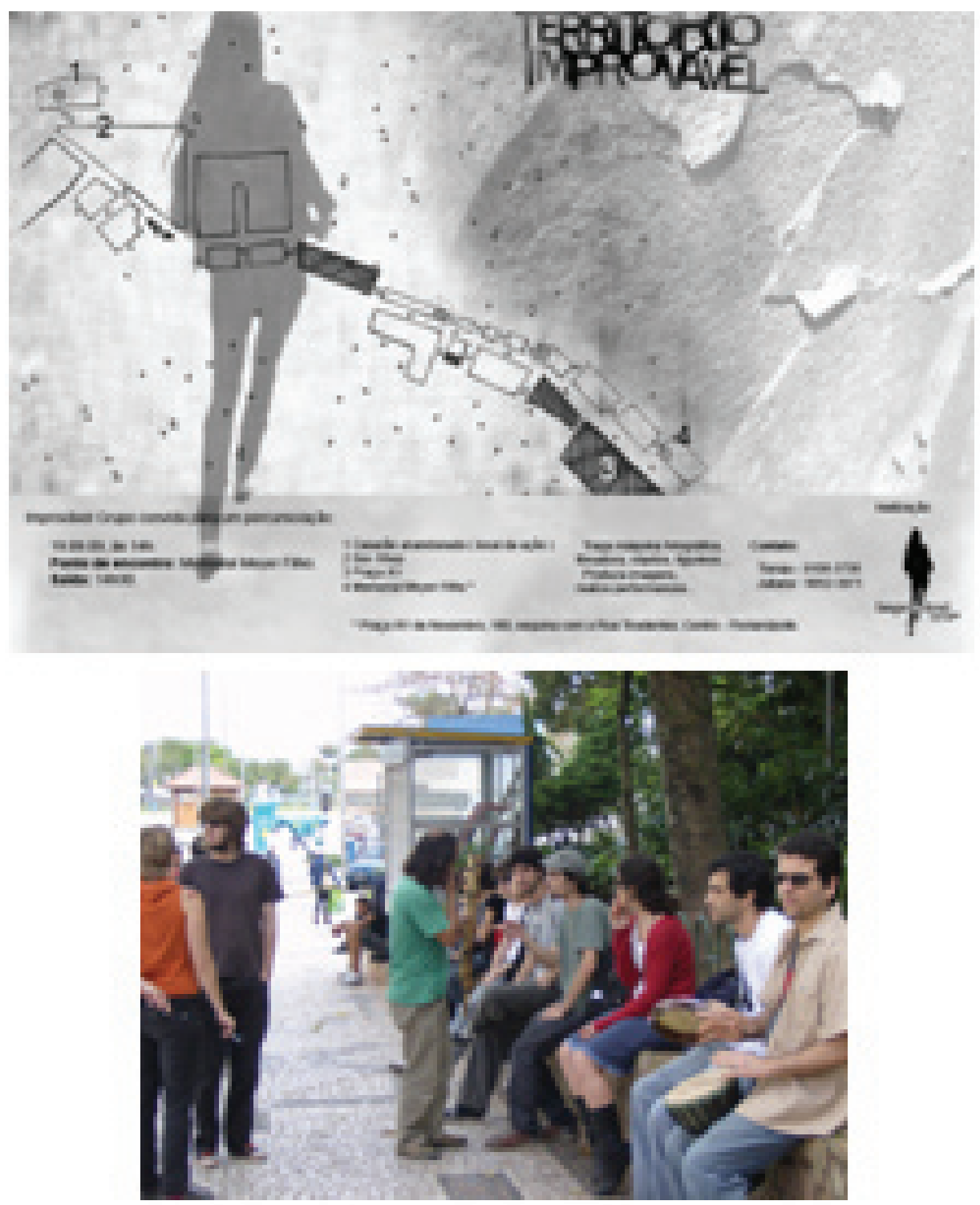



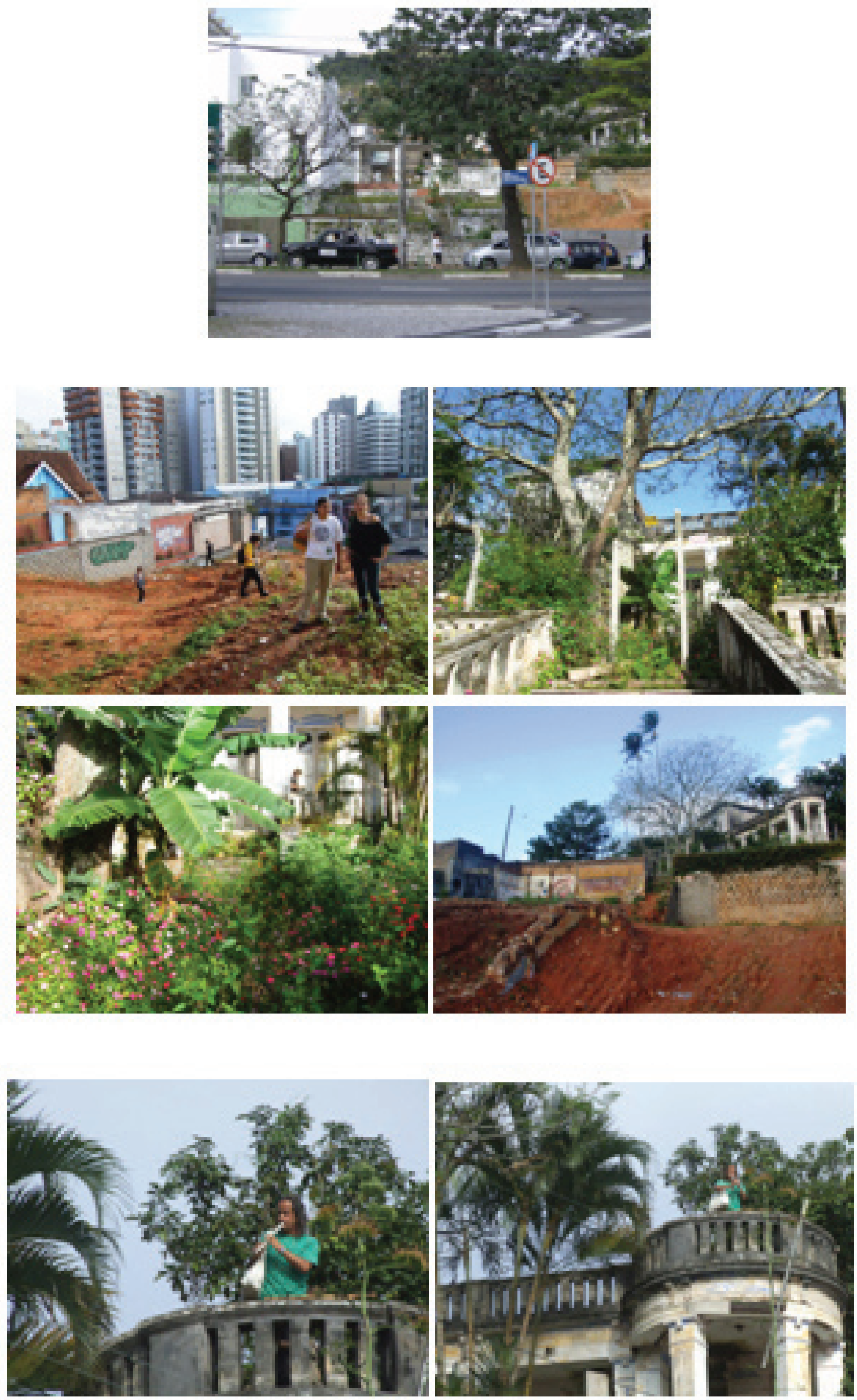

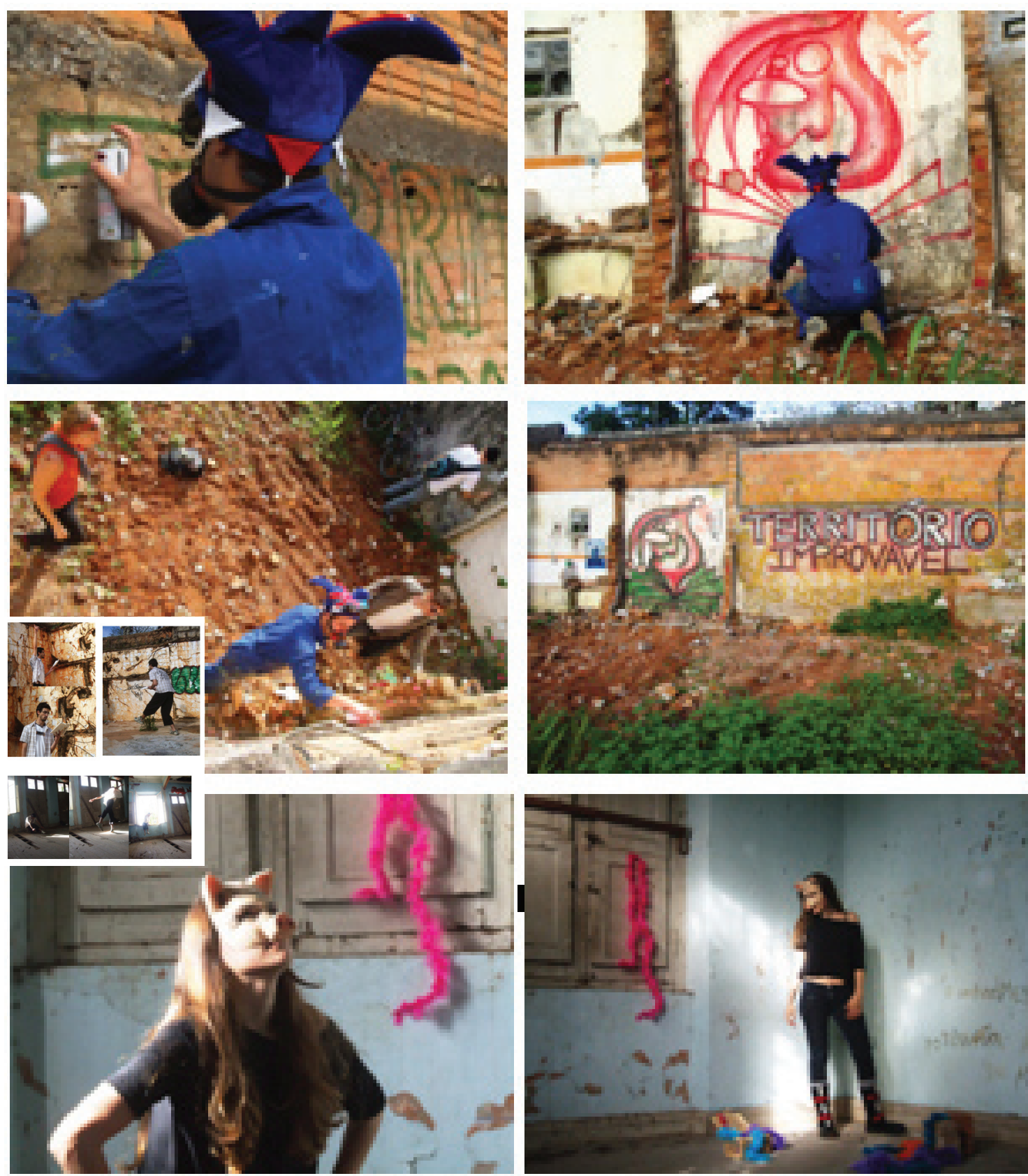

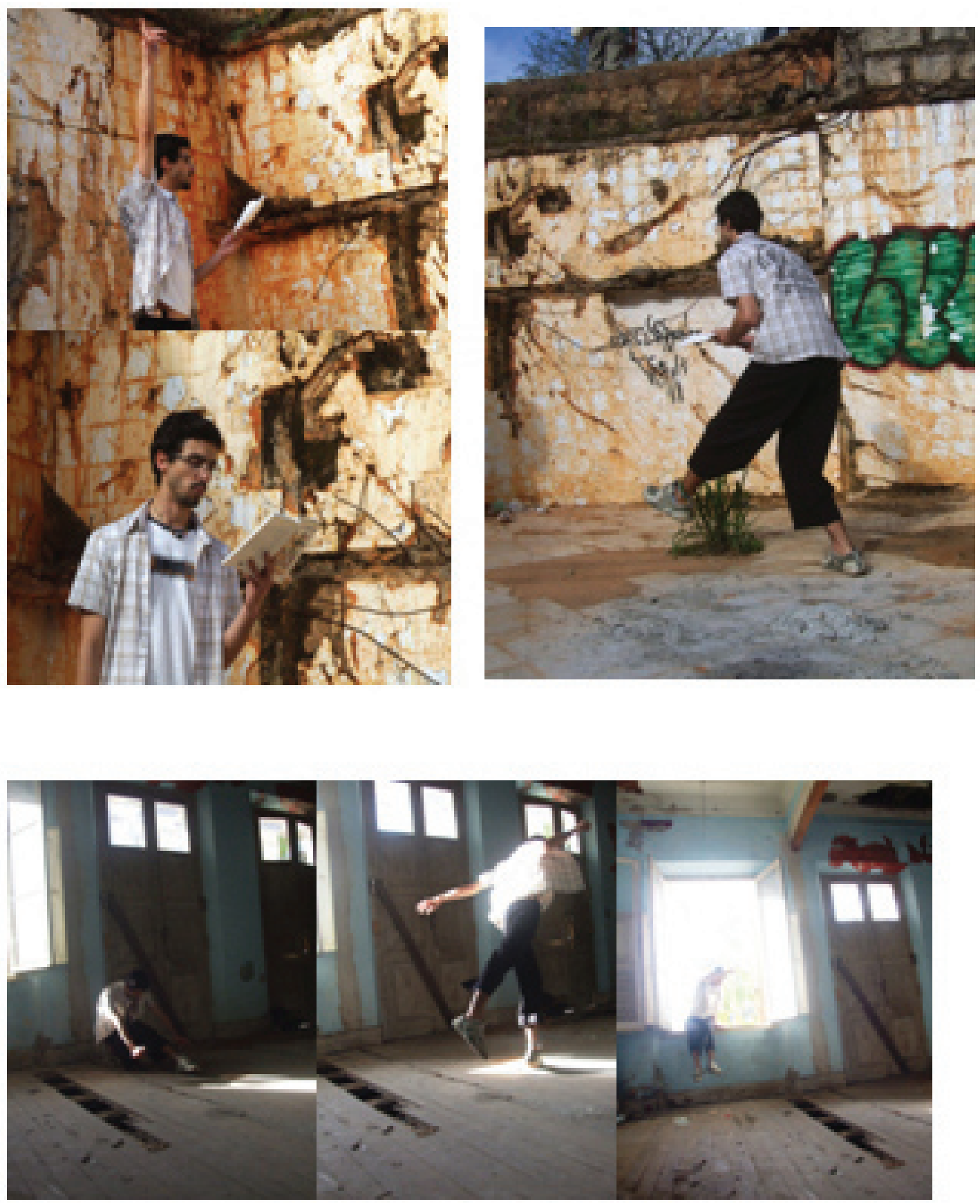

\section{Outro tempo provável}

Como fechamento deste projeto para este espaço específico, "Improvável Grupo" fará uma seleção de imagens, juntamente com os participantes do Percurso/Ação, imprimindo-as em cartazes e colando-as nos tapumes que estão presentes nos terrenos baldios, que ficam à frente deste Território Improvável.

A busca por novos territórios, novas ações e novas participações é um desafio proposto pelo grupo.

\section{Referências:}

BASBAUM, Ricardo. I love Etc-Artist. In: The next document should be curated by 
an artist. Frankfurt: Revolver Archiv für aktuelle Kunst, 2004.

BOURRIAUD, Nicolas. O que é um artista (hoje)? Revista Arte \& Ensaio - Revista do PPG em Artes Visuais EBA - UFRJ. Ano X - número 10/2003.

JACQUES, Paola Berenstein. Apologia da Deriva - Escritos Situacionistas Sobre a Cidade. Prefácio Carlos Roberto Monteiro de Andrade. Editora: Casa da Palavra, 2003.

LE PARC, Julio. Guerrilha Cultural? In: FERREIRA, Glória \& COTRIM, Cecília. Escritos

de artistas: anos 60/70. Rio de Janeiro: Jorge Zahar, 2006.

ROGÉRIO, Luiz. Arte de rede e arte do labirinto. Concinnitas - ano 7, volume 1, no 9, julho 2006. Revista do Instituto de Arte da UERJ.

Title:

An improbable territory for an improbable group. Actions around a space

\section{Abstract:}

This research proposes a reflection on the city, the oblivion, the photography, the actions generated by a group of young artists who has in common the passion for photography, for the history of photography, for photographic equipments, for the possibilities of image construction, be it by traditional methods or the technology available for us today. All that guided by the desire to create a photo-club by artists that look for the development of the possibilities of the photographic act with its artistic language working in many ways.

\section{Keywords:}

Photography; actions; city; Improbable Territory 